\title{
Results of Renogram and eGFRin Assessing Kidney Function of Chronic Kidney Disease Patients
}

\author{
Desery Randanan Pakiding ${ }^{1}$, Sugiarto Suwito², Hari Basuki Notobroto ${ }^{3}$ \\ ${ }^{1}$ Student, Department of Radiology, Faculty of Medicine, Universitas Airlangga, Dr. Soetomo Teaching Hospital, \\ Surabaya 62085, Indonesia, ${ }^{2}$ Lecturer in Department of Radiology, Faculty of Medicine, Universitas Airlangga, \\ Dr. Soetomo Teaching Hospital, Surabaya 62085, Indonesia, ${ }^{3}$ Lecturer in Department of Biostatistics and \\ Population, Faculty of Medicine, Universitas Airlangga, Dr. Soetomo Teaching Hospital, Surabaya 62085 , \\ Indonesia
}

\begin{abstract}
Background: The ability to assess kidney function properly has important health implications. Glomerular filtration rate (GFR) is still accepted as the best measurement index of kidney function. The formula of the Modified of Diet in Renal Disease (MDRD) is currently widely used by the medical community to estimate GFR (estimated GFR or eGFR). The renogram with radiofarmaka I131-Hippuran is considered to have an inherent accuracy of inulin cliren as the gold standard of GFR measurement.
\end{abstract}

Objective: To determine the description of renogram and eGFR's results in assessing kidney function of CKD patients.

Method: This study was a retrospective observational that used medical records from 113 CKD patients undergone renogram examination at Dr. Soetomo General Hospital Surabaya in 2012. eGFR was calculated based on the serum creatinine, age, and sex of the patient. Data of renogram and eGFR examination were presented descriptively.

Results: We obtained male of $63 \%$ and female of $37 \%$ with age range between $20-69$ years. The highest percentage in the age range of 50-59 years. The CKD cases in this study were mostly caused by urinary tract stones of $44 \%$. The most common renogram results were 2 kidney failure by $48 \%$ and the highest eGFR was $<15 \mathrm{ml} / \mathrm{min} / 1.73 \mathrm{~m} 2$ score of $73 \%$.

Conclusion: There were no normal results of renogram or eGFR. The most renogram results with 2 kidney failure were found in $48 \%$ of all aubjects with eGFR of $<15 \mathrm{ml} / \mathrm{min} / 1.73 \mathrm{~m} 2$.

Keywords: Chronic Kidney Disease, Renogram, eGFR

\section{Introduction}

Chronic kidney disease (CKD) is a world public health problem with a high incidence rate that is progressive and associated with disadvantageous outcomes. The prevalence of CKD in the United States increased from about $10 \%$ in $1988-1994$ to $13 \%$ in $1999-2004^{1,2}$. The US renal data system stated that the incidence of ESRD has continued to increase over the last 15 years, from 142 cases/million in 1987 to 308 cases/million in $2000^{2}$. There were 2.131 cases of CKD with hemodialysis inIndonesia (1995) which increased to 6.314 cases in $2004^{3}$.
GFR (glomerular filtration rate) is the best global index for renal function. GFR describes the flow rate of fluid that is filtered through the glomerular capillaries into Bowman's capsule per unit of time. The normal range of GFR is adjusted for body surface area of about 100-130 $\mathrm{ml} / \mathrm{min} / 1.73 \mathrm{~m} 2$ in male and female. GFR is measured with inulin clearance of about $110 \mathrm{ml} / \mathrm{min} / 1.73 \mathrm{~m} 2$ until the age of 2 years and then decreases. GFR decreases progressively by about $0.4-1.2 \mathrm{~mL} / \mathrm{min}$ per year at the age of $>40$. The available GFR calculation was eGFR or estimated GFR. The equation was obtained by using the regression technique to model the association 
between serum creatinine and GFR measurements in population studies. eGFR provides a substantial increase in serum creatinine examination for clinical assessment of renal function. Although the equations developed in one population are appropriate for its population, evaluation in other populations is needed to indicate the generalization of the observed association. Two creatinine-based equations have been studied and widely applied, namely the Cockcroft-Gault equation study and the Modification of Diet in Renal Disease (MDRD) $)^{1,4-}$ 7. The Cockcroft-gault formula was developed in 1973 with the equation $\mathrm{Ccr}=[(140$-age $) \times$ weight $/]$ $(72 \times \mathrm{Scr}) \times 0.85$ (if the subject was female), where $\mathrm{Ccr}$ is expressed in $\mathrm{ml} / \mathrm{min}$, age in year, body weight in $\mathrm{kg}$, and Serum creatinine (Scr) in $\mathrm{mg} / \mathrm{dl}$. It was exceeding GFR estimates systematically because they were not adapted to body surface $\operatorname{area}^{8}$. The latest formulation developed by The MDRD Study Group(1999) ${ }^{1,4}$ to measure GFR was the "4-variable MDRD" that used four variables, i.e., serum creatinine ( $\mathrm{mg} / \mathrm{dl})$, age (year), race, and sex. The estimated GFR (eGFR) was adjusted to the surface area of the body with the equation GFR $=186 \times(\mathrm{Scr})$ $1.154 \times($ age) $-0.203 \times 0.742$ (if the subject was female) or $\times 1.212$ (if the race of a subject was black skin). The validated formula of eGFR from Modified of Diet in Renal Disease (MDRD) is a formula that widely used by medical professionals (mainly the United States and the United Kingdom) to estimate GFR $^{9-11}$.

This formula has been validated in CKD patients; however, the usage is still uncertain in healthy patients with GFR $>60 \mathrm{ml} / \mathrm{min}$ or in patients with acute renal failure. Currently, most laboratories in Australia and the United States calculate and report MDRD-eGFR along with creatinine measurements. Inulin clearance is a gold standard for GFR measurements, but it is less used because of the method of examination and the unavailability of pure insulin. Further development of cliren of several radioisotope materials such as Chromium51-EDTA or Technetium99-DTPA, Iothalamate or Iohexol or I131Hippuran have an inherent accuracy of insulin cliren, thus they can be used instead of insulin cliren ${ }^{12,13}$. This study was conducted to obtain a description of the results of renal function evaluation of the renogram and eGFR calculation based on serum creatinine values in CKD patients.

\section{Method}

113 patients with CKD who underwent renogram in Dr. SoetomoTeaching Hospital Surabaya were enrolled in this study from April to December 2012. Renogram was a noninvasive examination to evaluate renal function by using radiofarmaka. CKD was a disease characterized by progressive and irreversible changes or impairment of renal function. Meanwhile, GFR was the volume of filtrate filtered from the glomerular capillaries into the Bowman capsule per unit time. The inclusion criteria in this study were CKD patients with a history of hemodialysis and CKD patients aged between $<20$ to 70 years old.

This study was a retrospective study by observing the medical record to obtain a description of Renogram and eGFR in assessing kidney function of CKD patients. Patients who have performed a Renogram examination on the Radio-Diagnostic Installation of Nuclear Medicine Division at Dr. SoetomoTeaching Hospital Surabaya were enrolled based on the inclusion criteria. The results of the Renogram examination showed as follows: 2 normal kidneys, 1 kidney obstruction, 2 kidney obstructions, 1 kidney obstruction-1 kidney failure, 1 kidney failure, and 2 kidney failure..

\section{Results}

113 CKD patients who fulfilled the inclusion criteria consisted of 43 females (38\%) and 70 males (62\%) with the highest distribution at the age range of 50-59 years by 38 patients $(66 \%)$ (Table 1$)$.

Table 1 Distribution of subjects of patients by age

\begin{tabular}{|c|c|c|c|}
\hline \multirow{2}{*}{ Age (Year) } & \multicolumn{2}{|c|}{ Sex } & \multirow{2}{*}{ Total (\%) } \\
\cline { 2 - 3 } & Male & Female & \\
\hline $20-29$ & 4 & 2 & $6(5 \%)$ \\
\hline $30-39$ & 13 & 6 & $19(17 \%)$ \\
\hline $40-49$ & 16 & 16 & $32(28 \%)$ \\
\hline $50-59$ & 24 & 13 & $37(33 \%)$ \\
\hline $60-69$ & 13 & 6 & $19(17 \%)$ \\
\hline Total & $\mathbf{7 0}$ & $\mathbf{4 3}$ & $\mathbf{1 1 3}(\mathbf{1 0 0} \%)$ \\
\hline
\end{tabular}

The most common cause in all subjects was urinary tract stones (44\%) (Table 2).

Table 2 Distribution of subjects by cause

\begin{tabular}{|l|c|c|}
\hline CKD Causes & Amount & Percentage \\
\hline Urinary tract stones & 50 & 44 \\
\hline Abdominal Tumors & 17 & 15 \\
\hline DM & 3 & 3 \\
\hline
\end{tabular}




\begin{tabular}{|l|c|c|}
\hline CKD Causes & Amount & Percentage \\
\hline Hypertension & 9 & 8 \\
\hline Urinary tract infection & 5 & 4 \\
\hline Etc. & 29 & 26 \\
\hline Total & 113 & 100 \\
\hline
\end{tabular}

Table 3 Distribution of Subjects by eGFR and Renogram

\begin{tabular}{|l|c|c|}
\hline & Frequency & Percentage \\
\hline eGFR (ml/min/1.73m2) & & \\
$>90$ & 0 & 0 \\
$60-89$ & 0 & 0 \\
$30-59$ & 9 & 8 \\
$15-29$ & 21 & 19 \\
$<15$ & 83 & 73 \\
\hline Total & $\mathbf{1 1 3}$ & $\mathbf{1 0 0}$ \\
\hline Renogram results & & \\
2 normal kidney & 0 & 0 \\
1 kidney obstruction & 1 & 1 \\
1 kidney failure & 1 & 1 \\
2 kidney obstruction & 19 & 16 \\
1 kidney failure-1 obstruction & 38 & 34 \\
2 kidney failure & 54 & 48 \\
\hline Total & $\mathbf{1 1 3}$ & $\mathbf{1 0 0}$ \\
\hline
\end{tabular}

Table 4 Distribution of eGFR by Sex and Age

\begin{tabular}{|l|c|c|c|c|c|c|}
\hline \multirow{2}{*}{ Variable } & \multicolumn{7}{|c|}{ eGFR(ml/min/1.73m2) } & \multirow{2}{*}{ Total } \\
\cline { 2 - 6 } & $>\mathbf{9 0}$ & $\mathbf{6 0 - 8 9}$ & $\mathbf{3 0 - 5 9}$ & $\mathbf{1 5 - 2 9}$ & $<\mathbf{1 5}$ & \\
\hline Sex & & & & & & \\
Male & 0 & 0 & 8 & 13 & 49 & 70 \\
Female & 0 & 0 & 1 & 8 & 34 & 43 \\
\hline Total & $\mathbf{0}$ & $\mathbf{0}$ & $\mathbf{9}$ & $\mathbf{2 1}$ & $\mathbf{8 3}$ & $\mathbf{1 1 3}$ \\
\hline \% Total & $\mathbf{0}$ & $\mathbf{0}$ & $\mathbf{8}$ & $\mathbf{1 9}$ & $\mathbf{7 3}$ & $\mathbf{1 0 0}$ \\
\hline Age: & & & & & & \\
$20-29$ & 0 & 0 & 0 & 1 & 5 & 6 \\
$30-39$ & 0 & 0 & 2 & 4 & 13 & 19 \\
$40-49$ & 0 & 0 & 1 & 6 & 25 & 32 \\
$50-59$ & 0 & 0 & 4 & 4 & 29 & 37 \\
$60-69$ & 0 & 0 & 2 & 6 & 11 & 19 \\
\hline Total & $\mathbf{0}$ & $\mathbf{0}$ & $\mathbf{9}$ & $\mathbf{2 1}$ & $\mathbf{8 3}$ & $\mathbf{1 1 3}$ \\
\hline \% Total & $\mathbf{0}$ & $\mathbf{0}$ & $\mathbf{8}$ & $\mathbf{1 9}$ & $\mathbf{7 3}$ & $\mathbf{1 0 0}$ \\
\hline
\end{tabular}

The renogram results found 54 subjects with two kidney failure that consisted of 36 males and 18 females. The most age range was 50-59 years of 16 subjects. There were no normal renogram results as the absence of normal eGFR results (>90 ml/min/1.73 m2). We obtained most of the renogram results with 2 kidney failure of 54 subjects and the highest eGFR of $<15 \mathrm{ml} /$ $\min / 1.73 \mathrm{~m} 2$ by 52 subjects (Table 5 ). 
Table 5 Distribution of Renogram by Sex, Age, eGFR

\begin{tabular}{|c|c|c|c|c|c|c|c|}
\hline \multirow[b]{2}{*}{ Variable } & \multicolumn{6}{|c|}{ Renogram } & \multirow[b]{2}{*}{ Total } \\
\hline & Normal & $\begin{array}{c}1 \text { kidney } \\
\text { obstruction }\end{array}$ & $\begin{array}{l}1 \text { kidney } \\
\text { failure }\end{array}$ & $\begin{array}{c}2 \text { kidney } \\
\text { obstruction }\end{array}$ & $\begin{array}{c}1 \text { kidney failure-1 } \\
\text { obstruction }\end{array}$ & $\begin{array}{l}2 \text { kidney } \\
\text { failure }\end{array}$ & \\
\hline Sex & & & & & & & \\
\hline Male & 0 & 1 & 1 & 14 & 18 & 36 & 70 \\
\hline Female & 0 & 0 & 0 & 5 & 20 & 18 & 43 \\
\hline Total & $\mathbf{0}$ & 1 & 1 & 19 & 38 & 54 & 113 \\
\hline$\%$ Total & $\mathbf{0}$ & 1 & 1 & 16 & 34 & 48 & 100 \\
\hline Age & & & & & & & \\
\hline $20-29$ & 0 & 0 & 0 & 0 & 1 & 5 & 6 \\
\hline $30-39$ & 0 & 0 & 0 & 5 & 6 & 8 & 19 \\
\hline $40-49$ & 0 & 0 & 0 & 5 & 12 & 15 & 32 \\
\hline $50-59$ & 0 & 0 & 0 & 9 & 12 & 16 & 37 \\
\hline 60-69 & 0 & 1 & 1 & 0 & 7 & 10 & 19 \\
\hline Total & $\mathbf{0}$ & 1 & 1 & 19 & 38 & 54 & 113 \\
\hline$\%$ Total & $\mathbf{0}$ & 1 & 1 & 16 & 34 & 48 & 100 \\
\hline eGFR & & & & & & & \\
\hline$>90$ & 0 & 0 & 0 & 0 & 0 & 0 & 0 \\
\hline $60-89$ & 0 & 0 & 0 & 0 & 0 & 0 & 0 \\
\hline $30-59$ & 0 & 0 & 1 & 5 & 3 & 0 & 9 \\
\hline $15-29$ & 0 & 1 & 0 & 6 & 12 & 2 & 21 \\
\hline$<15$ & 0 & 0 & 0 & 8 & 23 & 52 & 83 \\
\hline Total & $\mathbf{0}$ & 1 & 1 & 19 & 38 & 54 & 113 \\
\hline$\%$ Total & 0 & 1 & 1 & 16 & 34 & 48 & 100 \\
\hline
\end{tabular}

\section{Discussion}

It was in accordance with a previous research, most of CKD was caused by urinary tract stones (obstructive uropathy) by $44 \%$ of all subjects ${ }^{14}$. This result was in accordance with a research by Pais VM in 2007. The age range of most subjects was 50-59 years. According to research by Coresh et al, that there was a decrease of progressive GFR about $1 \mathrm{ml} / \mathrm{min} / 1.73 \mathrm{~m} 2$ per year after 30 years. It was also associated with the aging biological process that initiated structural and functional changes in the kidneys(8). No normal results of the renogram were found, it was in accordance with the absence of normal eGFR results $(>90 \mathrm{ml} / \mathrm{min} / 1.73 \mathrm{~m} 2)$. The most results of the renogram with two kidney failure were found in 54 patients. Most eGFR was found as many as $<15 \mathrm{ml} / \mathrm{min} / 1.73 \mathrm{~m} 2$ in 52 subjects. The renogram has more benefits because it can assess the kidney function separately.

Renogram results obtained 58 obstruction kidneys both in one kidney and two kidneys. It was in accordance with a research by Taylor AT in 2007 that mentioned the renogram was a non-invasive examination, especially to evaluate patients with suspicion of obstruction. Renogram as reference method had a number of limitations, especially in patients with severe renal dysfunction or patients with severe dilatation of the collecting system. Despite its limitations, this method was chosen because it was a non-invasive optional method in the context of clinical diagnostic impairment of renal function ${ }^{15-17}$.

\section{Conclusion}

There were no normal results of renogram or eGFR. The most renogram results with 2 kidney failure were found in $48 \%$ of all subjects with eGFR of $<15 \mathrm{ml} /$ $\mathrm{min} / 1.73 \mathrm{~m} 2$.

Ethical Clearance: This research is in accordance with ethical clearance, has not been published before and is not being considered for publication elsewhere.

Conflict of Interest: There is no conflict of interest in this study. 
Source of Funding: This research was carried out by a team and funded independently.

\section{References}

1. Levey AS, Stevens LA, Schmid CH, Zhang YL, Castro AF, 3rd, Feldman HI, et al. A new equation to estimate glomerular filtration rate. Annals of internal medicine. 2009;150(9):604-12.

2. Mark A, Perazella MD, F.A.C.P., Robert F, Reilly MD. Chronic Kidney Disease: A New Classification and Staging System. 2003:18-22.

3. Santoso D, Devianto N, Yogiantoro M. Chronic Kidney Disease-Mineral and Bone Disorders Laboratory Profiles in Chronic Haemodialysis Patients. Indian Journal of Public Health Research \& Development. 2019;10(4):1156-61.

4. Levey AS, Bosch JP, Lewis JB, Greene T, Rogers $\mathrm{N}$, Roth D. A more accurate method to estimate glomerular filtration rate from serum creatinine: a new prediction equation. Modification of Diet in Renal Disease Study Group. Annals of internal medicine. 1999;130(6):461-70.

5. Comparison of Asymmetric Dimethylarginine Levels Between Stages Three, Four, and Five Nondialysis of Chronic Kidney Disease.

6. Levey AS, Eckardt KU, Tsukamoto Y, Levin A, Coresh J, Rossert J, et al. Definition and classification of chronic kidney disease: a position statement from Kidney Disease: Improving Global Outcomes (KDIGO). Kidney international. 2005;67(6):2089-100.

7. Mallek R, et.al. Distinction between Obstructive and Non Obstructive Hydronephrosis : Value of Diuresis Duplex Doppler Sonography. AJR. 1996;166:113-7.

8. Coresh J, Selvin E, Stevens LA, Manzi J, Kusek JW, Eggers P, et al. Prevalence of chronic kidney disease in the United States. JAMA. 2007;298(17):203847.
9. Zuo L, Ma YC, Zhou YH, Wang M, Xu GB, Wang HY. Application of GFR-estimating equations in Chinese patients with chronic kidney disease. Am J Kidney Dis. 2005;45(3):463-72.

10. MacGregor MS. How common is early chronic kidney disease. Nephrology, dialysis, transplantation : official publication of the European Dialysis and Transplant Association - European Renal Association. 2007;22:8-18.

11. Lin EP, Bhatt S, Dogra VS, Rubens DJ. Sonography of Urolithiasis and Hydronephrosis. Ultrasound Clin. 2007;2:1-16.

12. Larsson M, Jagenburg R, Landahl S. Renal function in an elderly population. A study of S-creatinine, 51Cr-EDTA clearance, endogenous creatinine clearance and maximal tubular water reabsorption. Scandinavian journal of clinical and laboratory investigation. 1986;46(6):593-8.

13. Brown SCW. Nuclear Medicine Techniques. Urology C, editor. Edinburgh: Mosby; 2001. 139 $41 \mathrm{p}$.

14. Neugarten J, Acharya A, Silbiger SR. Effect of gender on the progression of nondiabetic renal disease: a meta-analysis. J Am Soc Nephrol. 2000;11(2):319-29.

15. Taylor AT. Kidney. Medicine CN, editor. Berlin: Springer - Verlag; 2007.

16. Hertanto DM, Ashariati A, Mardiana N, Santoso D. The Relationship between Estimated Glomerular Filtration Rate (EGFR) with Hepcidin in CKD Patients That Have Not Undergone Dialysis. Indian Journal of Public Health Research \& Development. 2019;10(4):1162-6.

17. Santoso D, Ludfi AS, Mardiana N. Association of Glomerular Filtration Rate with Intact Parathyroid Hormone in Non-dialysis Chronic Kidney Disease Patients. Indian Journal of Public Health Research \& Development. 2019;10(4):1167-71. 